\title{
The Pragma-Dialectical Analysis and Evaluation of Teleological Argumentation in a Legal Context
}

\author{
Eveline T. Feteris
}

Published online: 28 February 2008

(C) The Author(s) 2008

\begin{abstract}
In this article the author develops a framework for a pragma-dialectical reconstruction of teleological argumentation in a legal context. Ideas taken from legal theory are integrated in a pragma-dialectical model for analyzing and evaluating argumentation, thus providing a more systematic and elaborate framework for assessing the quality of teleological arguments in a legal context. Teleological argumentation in a legal context is approached as a specific form of pragmatic argumentation. The legal criteria that are relevant for the evaluation of teleological argumentation are discussed and translated in terms of critical questions that are relevant for the evaluation of the various forms of teleological argumentation.
\end{abstract}

Keywords Teleological argumentation · Pragmatic argumentation ·

Analysis of argumentation - Evaluation of argumentation - Critical question

\section{Introduction}

In law, judges often justify a legal decision by showing that this decision is instrumental in promoting a certain legal goal. From a functional perspective, legal rules can be considered as an instrument to realize certain legal, social and economic goals. These goals can be general legal goals and values such as 'general safety', 'community welfare', 'public health' or more specific goals of a particular legal system or branch of law. When a applying a legal rule in a concrete situation, a judge can justify this application from the perspective of its instrumental function in realizing a particular goal. He can do this by explaining that the consequences of

\section{E. T. Feteris $(\bowtie)$}

Department of Speech Communication, Argumentation Theory, and Rhetoric, University of Amsterdam, Spuistraat 134, 1012 VB Amsterdam, The Netherlands e-mail: e.t.feteris@uva.nl 
applying the rule in the concrete situation are acceptable from the perspective of this goal.

In legal theory, argumentation referring to the goals or purposes of a legal rule is called teleological argumentation. ${ }^{1}$ Judges use teleological argumentation in the context of the justification of the interpretation of a legal rule in a concrete case and argue that this interpretation can be justified from the perspective of the goal (telos) the rule is intended to realize.

Although in legal theory teleological arguments are widely discussed as a possible way of justifying a legal interpretation, no instrument is offered for the analysis and evaluation of teleological arguments in concrete decisions. To be able to establish whether a teleological argument is acceptable in a concrete case, it is important to determine whether the argument is a suitable argument for defending that particular decision and whether the argument itself is acceptable. In the legal literature, no comprehensive and systematic instrument for the analysis and evaluation of teleological argumentation is offered. Authors that go deeper into the analysis of concrete examples of teleological argumentation consider it as a form of single argumentation only consisting of one argument although, in legal practice, teleological argumentation always occurs as part of more complex argumentation in which consequences, goals and values are put forward as arguments in defence of a particular interpretation. Furthermore, no clear criteria are offered for the evaluation of such complex forms of argumentation.

The aim of this contribution is to develop a framework for the analysis and evaluation of teleological argumentation in a legal context. I will do this by integrating ideas taken from legal theory in a pragma-dialectical model for analyzing and evaluating argumentation, thus providing a more systematic and elaborate framework for assessing the quality of teleological arguments as they occur in complex justifications of legal interpretations. The pragma-dialectical theory offers a systematic theoretical basis for developing a model for the analysis and evaluation of argumentation in particular contexts. The general framework from pragma-dialectics about the analysis and evaluation will be implemented with legal insights to develop a model for the analysis and evaluation of teleological argumentation in the justification of legal decisions.

Section 2 characterizes teleological argumentation as a specific form of pragmatic/instrumental argumentation and describes how a model for the analysis and evaluation of teleological argumentation can be developed from a pragmadialectical perspective. Section 3 explains the function of teleological argumentation in a legal context. Section 4 discusses the various forms of teleogical argumentation distinguished in legal theory and reconstructs these forms as a specific implementation of pragmatic argumentation. Section 5 proceeds with describing the criteria which, from the perspective of legal theory, are relevant for the evaluation of legal argumentation and rephrases these norms from a

\footnotetext{
1 For the use of teleological argumentation in various legal systems in Europe, North America and South America see MacCormick and Summers (1991). Golding (1984) and Summers (1978) who discuss the use of various forms of legal argumentation in the US call teleological argumentation 'goal arguments'.
} 
pragma-dialectical perspective as critical questions relevant for the evaluation of the various forms of teleological argumentation.

\section{A Pragma-Dialectical Approach of Teleological Argumentation as a Specific Form of Pragmatic Argumentation}

From a pragma-dialectical perspective, teleological argumentation can be considered as a specific form of pragmatic argumentation. Therefore, to develop a model for the analysis and evaluation of teleological argumentation it is important first to determine the general characteristics of pragmatic argumentation.

In argumentation theory, pragmatic argumentation is considered as an argumentation scheme based on a specific form of a causal relation. ${ }^{2}$ It is argued that a particular action $\mathrm{X}$ is desirable or undesirable because it 'causes' certain desirable or undesirable effects. From a pragma-dialectical perspective, the basic form of this argumentation scheme can be represented as follows:

(1) Basic form of pragmatic argumentation

1 Action $\mathrm{X}$ is desirable

1.1a Action $\mathrm{X}$ leads to $\mathrm{Y}$

$1.1 \mathrm{~b} Y$ is desirable

Underlying this scheme is also the following implicit premise:

1.1c 'if action $\mathrm{X}$ leads to $\mathrm{Y}$ and $\mathrm{Y}$ is desirable, then action $\mathrm{X}$ is desirable'.

In pragmatic argumentation, the standpoint refers to a particular act X (which can be a decision, a proposal, a certain policy). In the most simple case where the consequences are not specified, the argumentation consists of a normative statement stating that consequence $\mathrm{Y}$ is desirable and an empirical statement stating that act $\mathrm{X}$ leads to consequence $\mathrm{Y}$. A similar scheme can be formulated for the negative variant in which it is argued that action $\mathrm{X}$ is undesirable, and combinations exist of elements of the positive and negative variant. ${ }^{3}$

Pragmatic argumentation is a general term for argumentation in which a course of action is defended by referring to its consequences. Depending on the way the consequences are presented, the argumentation can be analyzed as teleological or goal argumentation if the consequences are presented as the attainment of a particular goal, or as policy argumentation if the consequences are presented as the implementation of a particular policy. ${ }^{4}$

Often, pragmatic argumentation is part of a more complex argumentation. The (un)desirability of the consequences may be examined in the light of the desirability of certain goals. Those goals, in turn, can be defended by referring to certain values

\footnotetext{
${ }^{2}$ See van Eemeren and Grootendorst (1992).

${ }^{3}$ For a description of the various forms of pragmatic argumentation see Feteris (2002b).

4 As has been argued by various authors such as Garssen (1997) and Schellens (1985), it is not necessary to distinguish a specific argumentation scheme for these forms of argumentation because the types of critical questions relevant for the evaluation are similar. Another term often used for argumentation referring to the consequences of a course of action is 'practical argumentation'.
} 
and principles. In such cases, pragmatic argumentation is supported by other arguments. Pragmatic argumentation can also be supplemented by other arguments. It can be the case that pragmatic argumentation is, from the perspective of the arguer, a relevant and necessary reason for defending the desirability of a certain course of action, but that pragmatic argumentation is not sufficient and needs to be supplemented by other forms of argumentation such as ethical argumentation referring to the desirability of the course of action from an ethical perspective. ${ }^{5}$

From a pragma-dialectical perspective, for each type of argumentation scheme, in the evaluation specific critical questions are relevant. There are questions with respect to the adequacy of the argumentation scheme for defending a particular type of standpoint in a particular context, and there are questions with respect to the correct application of the argumentation scheme in the concrete situation.

For pragmatic argumentation, with respect to the adequacy of the use of the argumentation scheme the following question is relevant:

1 Is pragmatic argumentation an adequate way of defending this standpoint in this context?

For example, pragmatic argumentation is not adequate for defending a standpoint consisting of an empirical statement. Deriving an empirical conclusion from a normative statement would amount to committing the fallacy of argumentum ad consequentiam. $^{6}$

With respect to the correct application of the argumentation scheme in the concrete case the following questions are relevant:

2 Is consequence $\mathrm{Y}$ desirable?

3 Does action $\mathrm{X}$ lead to consequence $\mathrm{Y}$ ?

The answers to these critical questions may, in their turn, constitute new argumentation that can be a support or addition to the given argumentation. As I noted above, for example, pragmatic argumentation may be supported by arguments defending the desirability of Y (an answer to question 2) etcetera. With respect to these supporting arguments subsequent critical questions are relevant. Depending on whether the support also consists of pragmatic argumentation or of another type of argumentation, the critical questions for pragmatic or other types of argumentation are relevant.

For various forms of pragmatic argumentation and for the implementation of these forms in various contexts, it is necessary to investigate which norms are relevant for the evaluation and how these norms can be translated as critical questions for the evaluation.

For our purposes the perspective sketched above implies that it is necessary to investigate what teleological argumentation in a legal context exactly consists of, how it constitutes a specific implementation of general pragmatic argumentation and which critical questions are relevant for the evaluation. This implies that it must be

\footnotetext{
5 For a more extensive discussion of the function of pragmatic argumentation in complex forms of legal argumentation, see Feteris (2002a).

${ }^{6}$ See van Eemeren and Grootendorst (1992) and Walton (1999).
} 
established what the exact function of teleological argumentation is in a legal context, which forms can be distinguished, what the elements of teleological argumentation are, which norms for the evaluation apply, and how these norms can be formulated as various forms of critical questions.

\section{The Justification of Legal Decisions and Teleological Argumentation}

\subsection{The Rationale for Using Teleological Argumentation}

The rationale for using teleological argumentation can, as has already been said, be found in considering legal rules as an instrument for realizing certain legal, social and economical goals. ${ }^{7}$ Wróblewski (1992, pp. 103-107) states that legal regulation of human behavior aims at the implementation of specific values, which can be treated as the purposes of the law. From the perspective of a functional interpretation of legal rules, therefore, the functions of the rule, the purposes, should be taken into account. According to Lyons (1993, pp. 125-126) statutes can be understood as 'reasonable means to reasonable ends'. In his view, in order to establish the meaning of a legal rule for a concrete situation, in the interpretation the general aims or standards that are capable in justifying the statute, should be taken into account.

From such an instrumental or functional point of view, a legal rule is an instrument of social control. According to Wróblewski (1992), the application of legal rules results in certain consequences that can be considered as their 'functions'. The 'presupposed functions' are the results which ought to happen, the 'real functions' are the results which the rule has or will have according to proper predictions. In his view, in the judicial application of law, it is a ground for rejecting an interpretation of a rule if in that interpretation it would predictably have an undesirable effect, e.g. if it would result in consequences contrary to law or not purposeful, or paradoxical. In Lyons' view, the aim of a legal rule enables us to interpret the rule in such a way that its legal consequences are conducive to realizing this aim. MacCormick and Summers (1991, pp. 518-519) contend that the enactment of a statute can be seen as an instrument in the pursuit of some aspect of justice or public good. Such an actual or imputed end is the purpose of the statute. The purpose of the statute so understood is an evaluative ground for considering the consequences of possible interpretations as favorable or unfavorable for realizing the postulated purpose.

\footnotetext{
7 Considering legal rules as an instrument for realizing certain goals and values does not necessarily imply a instrumentalist or realist approach to judicial decision-making. In the US, the prevalent approaches of the application of law in legal theory in the twentieth century have been instrumentalism and legal realism. According to these theories, judges are not bound by the historic formulations of legal statutes and decisions but should look for the goals, the substantive reasons and rationales, of the rules to find a decision for the concrete case. For a discussion of these theories see for example Atiyah and Summers (1991). For a critique of radical instrumentalism see Lyons (1993, pp. 41-63). Lyons (1993, pp. 48-63) proposes a moderate instrumentalism.
} 
From a pragma-dialectical point of view we could say that teleological argumentation in the context of the application of legal rules could be considered as a specific form of pragmatic argumentation. It is argued that the consequences of application of the legal rule in the concrete case are desirable or undesirable from the perspective of the goal of the rule.

\subsection{Teleological Argumentation and the Interpretation of Legal Rules}

As has become clear, teleological arguments are often used in the justification of a decision in which a judge gives an interpretation of a particular legal rule. When a judge gives a decision, he must establish the meaning of the relevant legal rule(s) for the case at hand. In many situations, the meaning of the rule is clear in the context of the concrete situation, and the rule can be applied to the case without further interpretation. But there are also situations in which various interpretations of the rule for the concrete situation are possible. This makes it necessary for the judge to justify the chosen interpretation of the rule.

One of the methods a judge can use to interpret a legal rule is the method of teleological interpretation which implies that the judge establishes the meaning of the rule on the basis of the goal the rule is intended to realize. Teleological interpretation is often used when an interpretation based on the literal meaning of the rule (linguistic interpretation) or an interpretation based on the place of the rule within the legal system (systematic interpretation) does not offer an acceptable solution. Because legal rules are supposed to secure certain legal and social goals, teleological interpretation is an acceptable way of establishing the meaning of a rule. ${ }^{8}$

In their international research project on the use of various forms of argument used in justifying a legal interpretation MacCormick and Summers (1991, $518 \mathrm{ff}$ ) use the term teleological-evaluative argumentation for arguments that refer to the goals and values that are supposed to be realized by applying the legal rule. When giving a teleological-evaluative interpretation, a judge asks himself the question what the purpose of the rule is. From the perspective of the purpose he establishes how he can given an interpretation that is consistent with this purpose and how he can avoid giving an interpretation which would impede realizing the goal presupposed by the rule and the legal system as a whole. The goal of a rule can be considered as an evaluative ground on the basis of which possible interpretations can be considered as desirable or undesirable as a means to attain the postulated goal. ${ }^{9}$

Teleological arguments have an important function in justifying a choice between two or more possible interpretations. According to MacCormick and Bankowski (1991, pp. 370-371) in MacCormick and Summers (1991), arguments that deal with purposes pursued, can be used to test rival possible interpretations in the light of the probable consequences of their adoption. In their view, such

\footnotetext{
${ }^{8}$ MacCormick and Summers (1991, p. 537) remark that in various legal systems the degree of explicitness with which teleological arguments are stated in judicial opinions as grounds for interpretative conclusions vary. At one end of the spectrum of explicitness we find the French system (least explicit), with that of the USA at the other (most explicit).

9 For the use of teleological argumentation in Finland see MacCormick and Summers (1991, p. 141), France (1991, p. 181), Italy (1991, p. 228), Sweden (1991, p. 327), the UK (1991, p. 370).
} 
arguments can operate either as first-order interpretative arguments or as elements in second-order arguments.

First, teleological arguments can provide an argument for or against one or more possible interpretations of a disputed text or term. Second, teleological arguments may have a function as a justification of a priority among rival interpretations. These two uses of such interpretative arguments are not, in practice, easily separable. For the U.K. MacCormick and Bankowski (1991, pp. 384-385) say that all proposed interpretations are subject to challenge by teleological/evaluative arguments where their adoption will generate unacceptable consequences. Such an argument cannot justify a complete overriding of the words of the act in any possible linguistic meaning. But, given the constraints of the argument from possible meaning, consequentialist arguments and the values they invoke can be the finally justifying arguments in cases in which the solution cannot be found by referring to linguistic or systematic considerations. MacCormick and Summers (1991, p. 528) conclude that teleological arguments thus viewed, can be considered as 'canceling arguments' that may nullify the justificatory force of other arguments.

So, in cases in which the meaning of a legal rule is ambiguous or where two possible interpretations conflict, the rival consequences of one or the other interpretation may be the only rational ground available to support a choice one way or the other. An appeal to the consequences or purposes may show why one interpretation is better than its rivals because it favors more the goals and purposes of the rule than the other interpretations.

Different theoretical positions address the question about whose purposes should govern and what materials can be used in determining the goals or purposes. In a restricted approach of teleological interpretation, the material that can be used for determining the purpose in question is restricted to the so-called travaux préparatoires, the discussions in parliament and the written texts accompanying the statute that are produced during the discussion about the proposal in parliament. Because the history of a legal rule (in continental law systems consisting of the legislative history, in common-law systems consisting of past judicial decisions) is often ambiguous or unclear, the purposes and aims often have to be reconstructed. In a broader approach, the purpose or goal may also be reconstructed by referring to the rational goals or purposes of the rule. ${ }^{10}$

In their survey MacCormick and Summers (1991, pp. 519-520) conclude that in various countries a distinction is made between a subjective approach of legal interpretation saying that the aim of interpretation consists in finding out the historical legislator's actual purpose and intention, and an objective approach saying that the aim is to find the law's reasonable meaning, the purpose to be imputed to the legislature as an ideally rational legislator. The subjective approach involves giving priority to semiotic and genetic arguments, that is to the wording of the statute and the intention of the historical legislator. ${ }^{11}$ The objective approach keeps

\footnotetext{
10 Wróblewski (1992, p. 105) distinguishes static and dynamic theories of functional interpretation.

11 MacCormick and Summers (1991, p. 520) follow the terminology used in the German literature. Alexy (1991, p. 93) in MacCormick and Summers (1991) also distinguishes these two approaches.
} 
open the possibility that a judge gives priority to objective-teleological arguments and to other arguments based on rationality in general. ${ }^{12}$

The objective approach is, as MacCormick and Summers (1991, p. 519) argue, based on the idea that the legislature is an ideal legal institution not identical with any actual human being or party and hence the only decisions imputable to the legislature are those contained in acts of legislation. The purposes of statutes are to be gathered by reflecting on the rational ends attributable to an ideal legislator who in that historical and political conjuncture enacted this whole act with the provisions it makes and the design and structure it has. On this view, while travaux préparatoires will have some evidentiary value in elucidating the relevant historical and political background, they will have less compelling evidentiary value than in the former case. As MacCormick and Summers (1991, pp. 522-525) explain, in objective-teleological argumentation judges often refer to values which are considered to belong objectively to the legal order and hence to justify interpretations and decisions which impute to the legislature the intention of upholding fundamental values because of their fundamental character. Reasoning of this kind can be cast in terms of legislative intention or purpose, but such intentions or purposes are necessarily 'objective' ones.

\section{The Pragma-Dialectical Reconstruction of Teleological Argumentation}

In this section I will give a pragma-dialectical reconstruction of the structure and content of the general form of teleological argumentation and I will specify how the two forms of teleological argumentation, subjective and objective teleological argumentation, can be reconstructed. These reconstructions form the model that can be used in analyzing teleological argumentation in a legal context.

Alexy (1989, p. 237) formulates the following general argumentation scheme for teleological argumentation in a legal context $^{13}$ :

\footnotetext{
12 Alexy (1991, p. 88) observes that in Germany the formula with which a judge refers to the goal of a legal rule, which is often used in legal practice, is highly controversial in the literature. Critics argue that it gives too much freedom to the interpreter to read his own beliefs about right and reason into the norm. MacCormick and Summers (1991, p. 524) observe that an argument from intention is highly variable in content, indeterminate in itself and has a weight to be determined in the light of highly contentious issues in legal and linguistic theory, political philosophy and the philosophy of mind.

13 Peczenik (1989, pp. 404-405) formulates this general scheme from Alexy as follows:

Premise 1: Obtaining of the situation $\mathrm{Z}$ is prescribed

Premise 2: $\quad$ If one had hot do $\mathrm{H}$, then $\mathrm{Z}$ would not be obtained

Premise 3: If (1) obtaining of the situation $\mathrm{Z}$ is prescribed; and (2) if one had not do $\mathrm{H}$, then $\mathrm{Z}$ would not be obtained; then one should do $\mathrm{H}$

Conclusion: One should do $\mathrm{H}$
} 


\begin{tabular}{lll}
\hline (J.4.2) & (1) & $R$ is, for the legislator, a means to end $Z$ \\
& . (2) & Unless $R^{\prime}$ obtains, $Z$ does not obtain (that is, $R^{\prime}$ is a condition for $\left.Z\right)\left(-R^{\prime} 6-Z\right)$ \\
(3) & Interpretation $R^{\prime}$ is desirable $\left(R^{\prime}\right)$
\end{tabular}

Underlying this scheme is (S), the argumentation underlying the following rule of inference:

If it is mandatory to realize $\mathrm{Z}$ then whatever means are necessary for the realization of $\mathrm{Z}$ are also mandatory

that is necessary to make (J.4.2) complete:

\begin{tabular}{|c|c|c|}
\hline (S) & . (1) & It is mandatory that the state of affairs $\mathrm{Z}$ obtains $(\mathrm{OZ})$ \\
\hline & . (2) & Unless $M$ obtains, $Z$ does not obtain (that is, $M$ is a condition of $Z)(-M \quad 6-Z)$ \\
\hline & (3) & It is mandatory that $\mathrm{M}$ obtains $(\mathrm{OM})$ \\
\hline
\end{tabular}

Teleological argumentation refers to the consequences of the application of a legal rule and asks whether these consequences belong to the domain of presupposed consequences from the perspective of the goal of the rule. As such, teleological argumentation constitutes a specific legal implementation of pragmatic argumentation. Starting from the general scheme (1) for the basic form of pragmatic argumentation given above, this implementation can be represented as follows:

\section{(2a) Basic form of teleological argumentation}

Standpoint: Rule R must be interpreted as $\mathrm{R}^{\prime 14}$

Because: $\quad R^{\prime}$ is a means to attain goal $G$ and: $\quad$ Goal $\mathrm{G}$ is a goal the law ought to promote

The standpoint is a normative statement that rule $\mathrm{R}$ must be interpreted as $\mathrm{R}^{\prime}$, the argumentation consists of an empirical statement that interpretation $\mathrm{R}^{\prime}$ is a means to attain goal $G$ and a normative statement that goal $G$ is a goal the law ought to promote. This argumentation can be supported or supplemented by further argumentation as described by Alexy in (S).

Authors such as Alexy (1989, p. 236), MacCormick and Summers (1991, p. 524), Peczenik (1989, pp. 405-406) distinguish two forms of teleological argumentation: subjective-teleological argumentation and objective-teleological argumentation. ${ }^{15}$

\footnotetext{
${ }^{14}$ The formulation of the standpoint as 'Rule $\mathrm{R}$ must be interpreted as $\mathrm{R}^{\prime}$ ' is based on Alexy's formulation. Depending on whether the standpoint expresses a 'must' or 'ought' position, the standpoint can be formulated in various ways.

15 Another term used for subjective-teleological argumentation is genetic argumentation. Alexy (1989, p. 236) distinguishes two forms of genetic argumentation: the first occurs when it is said that the proposed interpretation is what the legislator directly intended, the second arises when it is claimed that the legislator adopted $\mathrm{R}$ as a means for advancing the goals $\mathrm{Z} 1$ etcetera and that $\mathrm{R}^{\prime}$ is necessary in order to bring about Z. Alexy remarks that this second form is in the form of teleological argumentation. Following Larenz, Alexy (1989, 240 ff) calls the second form of teleological argumentation also objective-teleological argumentation.
} 
The difference between the two forms of argumentation concerns the second argument that rule $\mathrm{R}$ is a means for attaining goal $\mathrm{G}$. When a judge uses subjectiveteleological argumentation he argues that the legislator has formulated rule $\mathrm{R}$ or has intended rule $\mathrm{R}$ as a means for attaining goal $\mathrm{G}$, and when a judge uses objectiveteleological argumentation he argues that goal $\mathrm{G}$ ought to be promoted by the law, that goal $\mathrm{G}$ is a rational goal objectively prescribed by the valid legal order.

The two forms of teleological argumentation can be reconstructed as two variants of the general form of teleological argumentation:

\section{(2b) Subjective-teleological argumentation}

$1 \quad$ Rule $\mathrm{R}$ must be interpreted as $\mathrm{R}^{\prime}$

1.1a $R^{\prime}$ is a means to attain goal $\mathrm{G}$

$1.1 \mathrm{~b}$ Rule $\mathrm{R}$ is intended by the historical legislator as a means to realize goal $\mathrm{G}$

(2c) Objective-teleological argumentation

$1 \quad$ Rule $\mathrm{R}$ must be interpreted as $\mathrm{R}^{\prime}$

1.1a $R^{\prime}$ is a means to attain goal $G$

$1.1 \mathrm{~b}$ Goal $\mathrm{G}$ is a rational goal objectively prescribed by the valid legal order ${ }^{16}$

Using the pragma-dialectical perspective it can be clarified that the two forms of teleological argumentation have a common structure and can be reconstructed as implementations of the general basic form of teleological argumentation. They only differ with respect to the argument $1.1 \mathrm{~b}$ in which it is specified from which perspective realization of the goal is desirable.

The argumentation schemes (2b) and (2c) are basic forms of subjective and objective teleological argumentation. In practice, there are various kinds of variations and extensions of these argument schemes. Extensions can be considered as subordinate arguments supporting the arguments of these basic forms which constitute an answer to a (possible) critique of this argument.

The reconstruction of the argumentation schemes (2a), (2b), and (2c) offers an instrument for the analysis of teleological argumentation in a legal context. The argumentation schemes specify the elements necessary for a justification of a legal decision based on a teleological interpretation. They form a heuristic tool in reconstructing the explicit and implicit elements of the argumentation put forward as a justification of a legal interpretation. As a critical tool they also specify the elements that should be submitted to rational critique.

As I have described in 2, the various forms of critique can be considered as critical questions with respect to the various parts of an argumentation scheme. In the following section, I will discuss the various norms for the use of teleological argumentation described in legal theory, and I will explain how these norms can be

\footnotetext{
16 Peczenik (1989, p. 407) formulates the argumentation scheme for objective-teleological argumentation as follows:

Premise 1: According to an interpretation, supported by various juristic, substantive and authority reasons, the provision $\mathrm{L}$, is a means to fulfill the goal $\mathrm{Z}$

Premise 2: If one had not interpreted $\mathrm{L}$ as containing the rule $\mathrm{R}$, then $\mathrm{Z}$ would not be obtained Conclusion: One should interpret $\mathrm{L}$ as containing the rule $\mathrm{R}$
} 
formulated as relevant critical questions for assessing the quality of teleological argumentation.

\section{Norms for the Use of Teleological Argumentation}

From a pragma-dialectical perspective, two kinds of critical questions are relevant for the evaluation. The first type of question asks whether the argumentation is an adequate way of defending a certain type of standpoint in a particular context and the second type of question asks whether the argumentation is applied correctly in the concrete case. To get a systematic view of the norms relevant for the evaluation of teleological argumentation in law, I will discuss the various ideas of the legal authors with respect to the correctness of teleological argumentation from the perspective of these two kinds of questions.

\subsection{Is Teleological Argumentation an Adequate Way of Defending a Legal Interpretation?}

The question whether pragmatic/instrumental argumentation in general is an adequate way of defending a legal standpoint is addressed by various authors in legal philosophy. As Many authors in modern legal philosophy representing an ethical-pluralist approach such as Bell (1983), MacCormick (1978) and Summers (1978) are of the opinion that in the justification of legal decisions two kinds of arguments play a role. ${ }^{17}$ Deontological or moral arguments are important to justify that the decision is coherent and consistent with relevant legal and moral rules and principles. Consequentialist, pragmatic or teleological arguments are important to justify that the proposed decision has consequences that are acceptable from the perspective of the goal of the rule.

In legal theory, the question whether teleological argumentation is an adequate way of defending a legal interpretation is approached from the perspective of the use of various interpretation methods. In their international research project on the methods of legal interpretation, MacCormick and Summers (1991) describe the preferred order for the use of various forms of interpretative arguments that can be inferred from the practices of legal justification in various countries. First, judges are supposed to look for linguistic arguments, referring to the meaning of the words and expressions used in the rule because this argument is the most close to the intention of the legislator. If such an argument offers no acceptable solution, a judge can look for systematic arguments referring to the position of the rule in the legal system and the relation with other rules because this argument still refers to the explicit words and intentions of the legislator. If also systematic arguments do not offer an acceptable solution, a judge can look for teleological-evaluative arguments which refer to the goals of the rule.

\footnotetext{
17 See Feteris (2002a).
} 
On the basis of this hierarchy, teleological arguments are only acceptable if the other arguments do not offer an acceptable solution. When a judge uses teleological argumentation, according to MacCormick and Summers (1991, p. 531) Alexy (1989, p. 248), Peczenik (1989, p. 407) a judge is obliged to justify why the other two forms of argumentation do not offer an acceptable solution. ${ }^{18}$ So, the first relevant critical question is:

1 Does the judge explain why a linguistic and a systematic interpretation do not offer an acceptable interpretation of rule $\mathrm{R}$ ?

If the justification consists of only a teleological argument the critical question 1 is relevant. ${ }^{19}$ If the teleological argument is presented as a supplement to other arguments such as for example a systematic argument, it is not necessary to answer question 1, because the decision does not only rest on the teleological argument.

Related to this point is the distinction between subjective and objective approaches of legal interpretation discussed in Sect. 3. With respect to the adequacy of teleological argumentation, these approaches result in different answers to the critical questions. If a judge uses objective-teleological argumentation the question can be asked whether it is allowed to take into account considerations based on the reasonable purposes of the law. If a critic adopts a subjective position, this question may be answered negatively if there are no other arguments supporting the interpretation. If a critic adopts a objective position, this question may be answered positively.

\footnotetext{
18 Atiyah and Summers (1991, pp. 101-102) see a difference between the English and the American doctrine in interpretation. According to them, the English doctrine requires the court to try to interpret statutory provisions in accord with the literal or plain meaning, and without regard to policies or rationales, unless the statute itself is first determined to be unclear. Most American judges, on the other hand, are willing to consider evidence of purpose in deciding whether the words are unclear in the first place. They remark, however, that this difference expresses a generalization which is not necessarily and always true of individual courts and judges. This so-called plain meaning approach may, according to them, well lead to great uncertainty, because the results may be so absurd that nobody can be quite sure if the courts really will stick to the 'plain meaning' interpretation.

Peczenik (1989, pp. 407-418) discusses the radical approach of interpretation of Ekelöf which claims that the teleological method is applicable since the very beginning of the interpretatory process. As Peczenik sketches, in the traditional approach of teleological interpretation, the teleological construction of a statute should be used only when aiming at reduction or creation of a more general new norm. The radical teleological approach claims that the teleological method is applicable to all kinds of interpretatory problems, also when performing a restrictive or extensive interpretation. In Peczenik's (1989, p. 418) view, Ekelöf's method diminishes the degree of coherence of legal reasoning and therefore the degree of legal certainty.

${ }^{19}$ In Feteris (2002a) I have explained that teleological argumentation can be used as only argument, but also as part of a more complex argumentation. Often judges use teleological argumentation as a reinforcement or addition to other arguments such as systematic arguments.

Drawing on these ideas, for the use of teleological argumentation in a legal context, a distinction must be made between situations in which the teleological argumentation offers the only positive support for the interpretation and situations in which teleological argumentation functions as a reinforcement of other arguments. Given this distinction, there are different critical questions relevant.
} 


\subsection{Has the Teleological Argumentation been Applied Correctly} in the Concrete Case?

From a pragma-dialectical perspective, various critical questions are relevant with respect to the various elements of the basic form of a teleological argument. These questions are:

2 Is goal $\mathrm{G}$ desirable?

3 Does interpretation $\mathrm{R}^{\prime}$ lead to realizing goal $\mathrm{G}$ ?

MacCormick (1978, pp. 262-263) adds another question:

4 Is $\mathrm{R}^{\prime}$ desirable as a means for realizing goal $\mathrm{G}$ ?

In what follows, I will address these three kinds of questions.

\subsubsection{Questions Concerning the Normative Argument: Is Goal G Desirable?}

The general question is:

2a Is goal $\mathrm{G}$ desirable?

In the two forms of teleological argumentation the desirability of the goal depends on different considerations.

For subjective-teleological argumentation, the desirability of the goal depends on whether this goal is to be found in the explicit formulation of the intention of the historical legislator in which he states that rule $\mathrm{R}$ is intended to attain goal G. With respect to this intention, Alexy (1989, pp. 238-239) and MacCormick and Summers (1991, $518 \mathrm{ff}$ ) note that it can sometimes be difficult to establish who is the subject of the 'will of the legislator' and what exactly is the 'will of the legislator'. Is the subject the totality of elected representatives in parliament?

For objective-teleological argumentation, the desirability of the goal depends on whether goal $\mathrm{G}$ can be considered as a rational goal in the valid legal order. Alexy (1989, pp. 242-243) and MacCormick (1978, p. 263) are of the opinion that for teleological argumentation an extra justification is required if for the description of the situation in which goal $\mathrm{G}$ can be considered as realized, further general norms or principles are required. They note that teleological argumentation always refers to a certain goal or desired state of affairs, but that that goal or state of affairs is never ad hoc but related to a general principle. Therefore, for a complete justification, in the ideal situation it is necessary to indicate on which general principles or values a goal is based. In this way, teleological argumentation becomes argumentation on the basis of principles.

With respect to the justification of teleological argumentation in general, Alexy (1989, p. 246, $284 \mathrm{ff}$ ) remarks that forms of teleological argument open up the field to general practical reasoning, because various elements of legal arguments may require further justification with arguments referring to considerations outside the legal context. The normative argument may be justified by using general practical 
considerations, and the choice between different interpretations leading to different results may require justification.

In relation to these considerations the following critical questions are relevant:

For subjective-teleological argumentation:

$2 \mathrm{aS}$ Is goal $\mathrm{G}$ indeed intended by the historical legislator?

For objective-teleological argumentation:

$2 \mathrm{aO}$ Is goal $\mathrm{G}$ indeed a rational goal objectively prescribed by the valid legal order and is goal $\mathrm{G}$ based on general legal principles and/or values underlying the legal order?

Various authors such as Alexy, Golding and MacCormick remark that goal G can be desirable in itself, but that there can be circumstances in which goal $G$ is incompatible with other goals of the legal system. A consequence could be that another interpretation which is consistent with these goals must be looked for, that an exception must be made, or that the rule must not be applied at all. In such situations the following critical question can be relevant ${ }^{20}$ :

2 b Is attaining goal $\mathrm{G}$ not inconsistent with other goals $\mathrm{G}^{\prime}, \mathrm{G}^{\prime \prime}$ etc.?

According to Alexy, in such situations rules of preference are necessary to indicate a hierarchy among the various goals. In such cases, there is also a critical question relevant about these rules of preference. As an answer, supporting argumentation is necessary which justifies why goal $\mathrm{G}$ is to be preferred above other goals $\mathrm{G}^{\prime}$ or $\mathrm{G}^{\prime \prime}$ :

2c If there are more goals rule $\mathrm{R}$ is supposed to realize, why is realization of goal $\mathrm{G}$ to be preferred above the realization of other goals?

\subsubsection{Questions Concerning the Empirical Argument: Questions Concerning the Relation Between Interpretation $R^{\prime}$ and Goal $G$}

The general formulation of the question relevant in relation to this argument is:

$3 \mathrm{a}$ Does interpretation $\mathrm{R}^{\prime}$ lead to realizing goal $\mathrm{G}$ ?

Depending on whether $\mathrm{R}^{\prime}$ is presented as a necessary, a sufficient or a necessary and sufficient condition, this question can be formulated in various ways.

\subsubsection{Interpretation $R^{\prime}$ is a Necessary Means for Realizing Goal G}

Golding (1984, p. 59) argues that often a particular goal $\mathrm{G}$ can be attained in various ways, so that neither $\mathrm{R}^{\prime}$ nor $\mathrm{R}^{\prime \prime}$ is a necessary means to realize $\mathrm{G}$. In that case a judge can decide that both interpretation $\mathrm{R}^{\prime}$ and $\mathrm{R}^{\prime \prime}$ are acceptable, or he can

\footnotetext{
${ }^{20}$ In these cases Golding (1984) proposes to reformulate the standpoint by including a reservation in the standpoint 'if there are no countervailing considerations, $\mathrm{R}^{\prime}$ ought to be recognized by the law'.
} 
establish an order of preference based on further considerations, like the principles and values mentioned above.

The relevant critical question with respect to the empirical argument in which $\mathrm{R}^{\prime}$ is presented as a necessary means for realizing goal $\mathrm{G}$ is:

3aNC Is $\mathrm{R}^{\prime}$ the only means for realizing goal $\mathrm{G}$ ? Are there other interpretations $\left(\mathrm{R}^{\prime \prime}\right.$ or $\left.\mathrm{R}^{\prime \prime \prime}\right)$ to realize goal $\mathrm{G}$ ?

If there is an order of preference among the various interpretations to realize goal $\mathrm{G}$, a following critical question is why the proposed interpretation offers a better way of realizing goal $\mathrm{G}$.

\subsubsection{Interpretation $R^{\prime}$ is a Sufficient Means for Realizing Goal G}

Alexy $(1989$, p. 242) argues that often goal $\mathrm{G}$ is not justified by one rule or norm, but by a group of rules and norms. In such cases, interpretation $\mathrm{R}^{\prime}$ is not a sufficient condition for realizing goal $\mathrm{G}$, there are more arguments necessary specifying the additional requirements for $G$. It is only sufficient to present one single rule as an argument for realizing $\mathrm{G}$ if the norm explicitly states the desirability of the goal. In this context the question is relevant whether $\mathrm{R}^{\prime}$ is a sufficient condition for realizing goal $\mathrm{G}$ or whether other conditions must also be fulfilled:

3aSC Are there any other factors which must be present together with $\mathrm{R}^{\prime}$ to realize goal $\mathrm{G}$ through $\mathrm{R}^{\prime}$ ?

If $\mathrm{R}^{\prime}$ is presented as both a necessary and sufficient condition for realizing goal $\mathrm{G}$, both questions $3 \mathrm{aNC}$ and $3 \mathrm{aSC}$ are relevant.

3 Questions concerning the desirability of $R^{\prime}$ as a means for realizing goal $G$

MacCormick (1978, p. 263) indicates that a third type of question is relevant with respect to the desirability of goal arguments. Regardless of the efficacity of $R^{\prime}$ as a means to realize $\mathrm{G}$, on other grounds it can be undesirable to choose for interpretation $\mathrm{R}^{\prime}$ or to choose $\mathrm{R}^{\prime}$ as a means to realize $\mathrm{G}$. A relevant critical question in this context can be:

4a Does interpretation $\mathrm{R}^{\prime}$ have any undesirable side-effects?

Furthermore, MacCormick and Summers (1991, p. 523) are of the opinion that the proposed interpretation must be coherent and consistent with relevant legal values and principles:

$4 \mathrm{~b}$ Is $\mathrm{R}^{\prime}$ coherent and consistent with relevant legal values and principles?

In this section I have explained how the various forms of critical questions that are relevant for evaluating pragmatic argumentation can be implemented for the various forms of teleological argumentation in a legal context. I have specified how the norms which, from the perspective of legal theory, are relevant for the evaluation of teleological argumentation, can be rephrased in the form of critical questions for the evaluation from a pragma-dialectical perspective. 


\section{Conclusion}

In this paper I describe the role of teleological argumentation in a legal context and the way in which this specific form of pragmatic argumentation can be analyzed and evaluated in an adequate way. I develop a pragma-dialectical model that provides a heuristic tool in analyzing teleological argumentation in a legal context and I specify how this model, in combination with the relevant critical questions, can serve as a critical tool for rational critism of teleological justifications.

Teleological argumentation has a function in the justification of a legal decision when a judge wants to show that the preferred interpretation of a legal rule in a concrete case contributes to attaining the purpose or goal the rule is supposed to realize. The judge argues that the consequences of application in the concrete case are desirable or undesirable in the light of the purpose or goal.

By using a pragma-dialectic perspective I have clarified the function that the various arguments, the normative argument and the empirical argument, have in the justification of the interpretation and which kinds of arguments can be relevant in supporting the two kinds of argument as an answer to (possible) critical questions.

The normative argument in which a judge refers to the desirability of the goal links the argumentation to the legal system by stating that the goal is desirable from a legal perspective. In subjective-teleological argumentation the desirability is based on the exact words and on the intention of the historical legislator, and the question is relevant where this intention can be found. In objective-teleological argumentation the desirability is based on values and principles underlying (part of) the legal system, and the question is relevant which legal principles and values underlying the legal system justify the claim that this goal is underlying this particular rule.

The empirical argument can take on different forms, depending on whether the interpretation is presented as a necessary, a sufficient, or a necessary and sufficient condition. If $\mathrm{R}^{\prime}$ is presented as a necessary condition, it is relevant to ask whether the proposed interpretation is the only way to realize a particular goal. If $\mathrm{R}^{\prime}$ is presented as a sufficient condition, it is relevant to ask whether there are other factors which must be present to realize this goal through $\mathrm{R}^{\prime}$.

Furthermore there are two questions with respect to the desirability of $\mathrm{R}^{\prime}$, regardless of the efficacity of $\mathrm{R}^{\prime}$ for realizing goal $\mathrm{G}$. The first question is whether interpretation $\mathrm{R}^{\prime}$ has undesirable side-effects. The second question is whether interpretation $\mathrm{R}^{\prime}$ is coherent and consistent with relevant legal values and principles.

We have seen that teleological argumentation is used in the context of the justification of the interpretation of a legal rule. The rationale for the use of teleological argumentation is that it is a way of showing that the application of the rule in the concrete case is instrumental in realizing certain legal, social and economical goals. By putting forward teleological argumentation, the judge shows how the interpretation of the legal rule contributes to realizing these goals.

I explain that in legal theory two forms of teleological argumentation, subjective and objective teleological argumentation, are distinguished. Therefore, in evaluating the justification of a legal interpretation for the different forms different critical questions can be relevant. With respect to the desirability of the goal different critical questions are relevant with respect to the reasons why the judge thinks that a 
particular goal is desirable. From the perspective of subjective-teleological argumentation, the question is relevant whether the goal is intended by the historical legislator. From the perspective of objective-teleological argumentation, the question is relevant whether the goal is a rational goal prescribed by the valid legal order. In the context of objective-teleological argumentation, a further question can be relevant whether this goal is based on general legal principles and/or values.

The integration of the pragma-dialectical and legal-theoretical perspective proves to be fruitful in two directions. For legal theory, the pragma-dialectical perspective allows for a distinction between various types of norms for the use of teleological argumentation. It has been demonstrated which norms can be considered as relevant for critical questions relating to the adequacy of teleological argumentation as an argumentation scheme and which norms can be considered as relevant for critical questions relating to the correct application of the argumentation scheme. The description of the function of the various elements of the argumentation scheme clarifies why for the normative argument different forms of critique are relevant than for the empirical argument.

For pragma-dialectics the integration allows for a better understanding of the ways in which the various evaluation questions can be implemented. It can be explained that certain questions relating to a correct choice or the correct application of an argumentation scheme can be related to the specific conception of reasonableness underlying the norms applied in assessing the quality of the argumentation. From the perspective of legal philosophy, the adequacy of teleological argumentation depends on whether a critic adopts a purely teleological, a purely deontological, or an ethical-pluralist approach. From the perspective of legal theory, the adequacy of the subjective vs. the objective variant of teleological argumentation depends on whether a critic represents a subjective or an objective approach of legal interpretation. Furthermore, value hierarchies underlying the preference for one particular goal above another goal and value hierarchies underlying the application of general principles and values in assessing the desirability of a goal are based on conceptions about the function of law in society.

Integration of the two perspective makes it possible to give a rational reconstruction of the various arguments which must be put forward in support of the various parts of teleological argumentation. Further research must show how these considerations are taken into account in the analysis and evaluation of actual examples of complex forms of justifications of judicial decisions.

Open Access This article is distributed under the terms of the Creative Commons Attribution Noncommercial License which permits any noncommercial use, distribution, and reproduction in any medium, provided the original author(s) and source are credited.

\section{References}

Alexy, R. 1989. A theory of legal argumentation. The theory of rational discourse as theory of legal justification. Oxford: Clarendon Press (Translation of Theorie der juristischen Argumentation. Die Theorie des rationalen Diskurses als Theorie der juristischen Begründung. Frankfurt a.M.: Suhrkamp, 1978). 
Alexy, R. 1991. Statutory interpretation in the Federal Republic of Germany. In Interpreting statutes. A comparative study, eds. N. MacCormick and R.S. Summers. Aldershot: Dartmouth.

Atiyah, P.S., and R.S. Summers. 1991. Form and substance in Anglo-American law. A comparative study of legal reasoning, legal theory, and legal institutions. Oxford: Clarendon Press (first edition 1987).

Bell, J. 1983. Policy arguments in judicial decisions. Oxford: Clarendon Press.

Feteris, E.T. 2002a. The role of arguments from consequences in legal argumentation. In Argumentation and its applications. Proceedings of the OSSA conference on argumentation, Windsor, May 17-19 2001 (CD-rom), eds. H.V. Hansen and C. Tindale.

Feteris, E.T. 2002b. A pragma-dialectical approach of the analysis and evaluation of pragmatic argumentation in a legal context. Argumentation 16(3): 349-367.

Garssen, B. 1997. Argumentatieschema's in pragma-dialectisch perspectief (Argumentation schemes in pragma-dialectical perspective). Amsterdam: IFOTT.

Golding, M. 1984. Legal reasoning. New York: Knopf.

Lyons, D. 1993. Moral aspects of legal theory. Essays on law, justice, and political responsibility. Cambridge: Cambridge University Press.

MacCormick, D.N. 1978. Legal reasoning and legal theory. Oxford: Clarendon Press.

MacCormick, N., and Z. Bankowski. 1991. Statutory interpretation in the United Kingdom. In Interpreting statutes. A comparative study, eds. N. MacCormick and R.S. Summers. Aldershot: Dartmouth.

MacCormick, N., and R.S. Summers. 1991. Interpreting statutes. A comparative study. Aldershot: Dartmouth.

Peczenik, A. 1989. On law and reason. Dordrecht: Kluwer.

Schellens, P.J. 1985. Redelijke argumenten (Reasonable arguments). Dordrecht: Foris.

Summers, R.S. 1978. Two types of substantive reasons: The core of a theory of common-law justification. Cornell Law Review 63: 707-788.

van Eemeren, F.H., and R. Grootendorst. 1992. Argumentation, communication and fallacies. Hillsdale, NJ: Erlbaum.

Walton, D. 1999. Historical origins of Argumentum ad consequentiam. Argumentation 13(3): 251-264.

Wróblewski, J. 1992. The judicial application of law, eds. Z. Bankowski and N. MacCormick. Dordrecht: Kluwer. 